\title{
Hydroxyzine and shock in operant behavior of rats*
}

\author{
VLADIMIR PISHKIN and ELIZABETH A. RASMUSSEN \\ VA Hospital and University of Oklahoma School of Medicine \\ Oklahoma City, Okla. 73104 \\ and \\ CARLA R. DUKE \\ Vassar College, Poughkeepsie, N.Y. 12601
}

A total of 25 shaped or unshaped water-deprived rats injected with either saline or hydroxyzine-hydrochloride performed on a barpressing task. Unavoidable shock was provided throughout the experimental procedure. Hydroxyzine rats outperformed their saline counterparts. Although there were no differences between the groups on the final shaping trial, the hydroxyzine rats maintained significantly higher levels of performance than the saline rats under shock conditions.

During the past 10 years, hydroxyzine-hydrochloride (Vistaril) has been receiving considerable attention by researchers in induced-stress experiments and clinical investigations with psychiatric patients. A number of studies have demonstrated tranquilizing and analgesic effects as well as low toxicity of this drug. Hughes \& Kopmann (1960) found that hydroxyzine reduced stress in rats without impairing their discrimination in an unavoidable shock situation in a shuttlebox. More recently, Pishkin, Shurley, \& Wolfgang (1967) tested the effects of hydroxyzine with psychiatric patients on a concept identification $(\mathrm{Cl})$ task under stress, combining unavoidable failure on an antecedent $\mathrm{CI}$ task concomitant with conditioning of GSR anticipatory response to unavoidable electric shock. Their results showed that hydroxyzine facilitated recovery from the stress as evidenced by performance, conductance changes in GSR, and muscle action potentials. However, utilizing rats with a relatively high dosage of hydroxyzine $(50 \mathrm{mg} / \mathrm{kg}$ of body weight), Pishkin, Rasmussen, \& Duke (1968) have shown reduction in barpressing rates of rats in a sensory-deprivation experiment where it was expected that inhibitory effects of stress, as a function of sensory deprivation (Pishkin \& Shurley, 1969), would be reduced with hydroxyzine. Since avoidable and unavoidable electric shock is known to produce stress and interference with learning (e.g., Pishkin, Shurley, \& Wolfgang, 1967), this study was conceived to investigate interactive effects of hydroxyzine and unavoidable shock upon positively reinforced barpresses of the rat. Comparison of results from this experiment with rats with those of Pishkin et al (1967) with humans was anticipated to shed some light on the tranquilizing

* Hydroxyzine-hydrochloride (Vistaril) was provided by Pfizer Laboratories, N.Y. effects of hydroxyzine upon operant behavior, shaped and unshaped, with concomitant unavoidable stress.

\section{SUBJECTS}

Twenty-five Holtzman-strain albino rats served as Ss. The weight range was between 192 and $250 \mathrm{~g}$ with a mean weight of $217.50 \mathrm{~g}$. The rats were approximately 60 days old at the time of the study; they were caged in pairs and were on ad lib diet. Only those rats producing a minimum of 50 water-reward barpresses within $1 \mathrm{~h}$ after $46 \mathrm{~h}$ of water deprivation were included in the experiment.

\section{APPARATUS}

A Stoelting Skinner box with a lever and a water-reward dipper $(.02 \mathrm{cc})$ illuminated with a $15 . \mathrm{W}$ bulb was used. The unavoidable electric shock $(50 \mathrm{~V})$ was delivered to the grid floor at time intervals varying regularly from 1 to $5 \mathrm{~min}$ (1-5-2-4-3 min repeated) with an average interval of $3 \mathrm{~min}$. The times of shock and barpresses were recorded on the Hunter-210 pen marker and the shock time intervals were regulated by a motor-driven cam Industrial Timer (RCK-1).

\section{DESIGN AND PROCEDURE}

This was a 2 by 2 factorial design. Five rats were assigned randomly to each of the cells with two training (shaped or unshaped) and two drug (hydroxyzine or saline) conditions. All rats were deprived of water for $46 \mathrm{~h}$ before each session, including the preexperimental training sessions. A dipperfull $(.02 \mathrm{cc})$ of water could be obtained by pressing a bar in the Skinner box.

\section{Shaped Group}

Two groups (hydroxyzine and saline) of five rats each were allowed to remain undisturbed in the Skinner box for $60 \mathrm{~min}$ after their first 50 barpresses to obtain water reward. With a maximum of 15 days, a second shaping session in the Skinner box was provided to the same rats, again lasting $60 \mathrm{~min}$ after the 50th response. One hundred and sixty-eight hours after this second session, the $S$ was placed in the Skinner box for a third time. After the 50th response, either drug or the placebo was administered for the experimental run. Unshaped Group

The other two groups of five rats each were placed in the Skinner box only once. On their 50th response of this first session, the experimental drug conditions were initiated.

\section{Experimental Run}

Both shaped and unshaped rats were subjected to the same procedure. The $S$ was removed immediately after the 50th barpress, and injected behind the right front leg, subcutaneously, with either $20 \mathrm{mg} / \mathrm{kg}$ of body weight of hydroxyzine or with an equal volume $/ \mathrm{kg}$ of body weight of saline solution. The injection was regarded as time " 0 " in the experiment. The $S$ was then handled for approximately $1 \mathrm{~min}(+1)$ and placed back in to the Skinner box. Ten minutes after injection $(+10)$ a shock timer was turned on that delivered a $50-\mathrm{V}$ shock through the metal grid floor of the Skinner box for the duration of $2 \mathrm{~min}$. The interval between shocks varied ( 1 to $5 \mathrm{~min}$ ) on the repeating interval schedule. The first shock was delivered at +11 min and the shock was repeated for $1 \mathrm{~h}$ according to the repeated interval schedule, giving the $S$ a total of 20 2 -min shocks. The $S$ was removed after the 20 th shock, $+70 \mathrm{~min}$.

\section{RESULTS AND DISCUSSION}

The results are based on the analyses of barpress responses on the second shaping and the experimental runs in hydroxyzine and saline conditions. The analysis of variance on the total number of responses on the experimental run revealed that the main effect of drug was significant $(\mathrm{F}=6.82, \mathrm{df}=1 / 17, \mathrm{p}<.01)$. As seen in Fig. 1, the hydroxyzine groups consistently out-performed their shaped and unshaped counterparts.

The main effect of shaping was also significant $\quad(F=16.21, \quad d f=1 / 17$, $\mathrm{p}<.001)$; unshaped rats produced significantly fewer responses. The

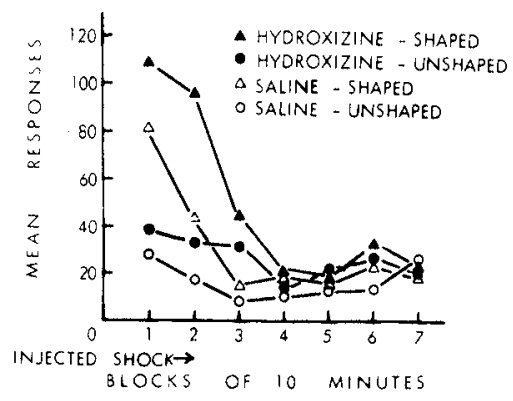

Fig. 1. Mean number of responses by the four groups. Each point represents five Ss. 


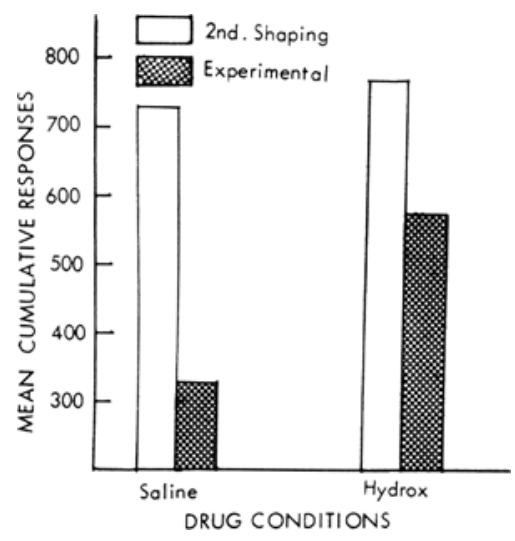

Fig. 2. Mean cumulative repsonses by the shaped rats on the second shaping and experimental runs.

Drug by Shaping interaction was not significant. It is clear in Fig. I that the drug and shaping main effects were due to the differences obtained during the first $30 \mathrm{~min}$ in the box. When analysis of variance was performed on the last four blocks of trials, no reliable differences were found between the four groups $(F<1.00)$. These findings clearly demonstrate that the inhibiting effects of shock were minimized by hydroxyzine, as reflected in the operant behavior of the water-deprived rats.

Equally important was the significant difference demonstrated within shaped $\mathrm{Ss}$ between number of barpresses on the second shaping run and experimental shock condition of the saline group $(F=4.86$. $\mathrm{df}=1 / 17, \mathrm{p}<.05)$. However, there was no significant difference in barpress rate between shaping and the experimental runs of the hydroxyzine conditions, indicating reduction of inhibiting stress effects of shock by injection of hydroxyzine. Furthermore, a significant interaction between Runs (second shaping and experimental) by Drug conditions was found $(F=9.32$, $\mathrm{df}=1 / 17, \mathrm{p}<.01)$, as shown in Fig. 2.

It is clear that, although the effect of shock was to significantly reduce the number of barpress responses from the second shaping run level in both drug groups, hydroxyzine mitigated inhibiting effect of shock upon this particular operant response. It is also noteworthy that there were no significant differences between saline and hydroxyzine rats on the second shaping run $(t=1.03, d f=8$, $\mathrm{p}<.05)$. An additional five control rats were run in the box meeting the shaping criterion, only no shock was administered during the experimental run; this control group was compared to the two unshaped groups, demonstrating superior performance of the controls over the saline and the hydroxyzine groups $(F=4.13$, $\mathrm{d} f=2 / 13 . \mathrm{p}<.05$ ). The mean cumulative responses were +82.80 .127 .40 . and 186.40 for the shaped control, unshaped saline. and hydroxyzine groups, respectively.

Thus, it is concluded that shock does significantly inhibit response rates of both drug-group $S$ s that were not exposed to shaping runs. As suggested in an earlier study (Pishkin, Rasmussen, \& Duke, 1968), hydroxyzine acts to maintain previously learned behavior under stress at a slightly reduced rate, whereas in the early stages of operant conditioning the effect of shock upon the saline group is to reduce operant rates significantly.

\section{REFERENCES}

HLGHES, F. W., \& KOPMANN, F. Influence of phenobarbital, hydroxyzine, chlorpromazine, reserpine and meprobamate on choice-discrimination behavior in the rat. Archives of International Pharmacodynamics, $1960,126,158.170$.

PISHKIN, V., RASMUSSEN, E. A., \& DUKE, C. R. Effects of sensory deprivation and hydroxyzine on rats' bar pressing. Psychonomic Science, 1968, 10, 255-256.

PISHKIN, V., \& SHURLEY, J. T. Hydro-hypodynamic sensory isolation effects on concept identification. Journal of Experimental Psychology, 1969, 82, 198-204. PISHKIN, V., SHLRLEY, J. T., \& WOLFGANG A. Stress. Archives of General Psychiatry, $1967,16,471-478$. 